\title{
The Be SMART Initiative: Educating Communities on Safe Gun Practices
}

\section{Johanna Thomas ${ }^{1 *}$, Jennifer Chappell-Deckert ${ }^{2}$, Shaun Thomas $^{3}$}

${ }^{1}$ Associate Professor, School of Social Work, University of Arkansas, 112 W. Center St., Room 408, Fayetteville, AR 72701, United States.

${ }^{2}$ Assistant Professor, School of Social Work, Bethel College, 300 East 27th Street, North Newton, Kansas 67117, United States.

${ }^{3}$ Associate Professor, Department of Sociology and Criminology, University of Arkansas, Fayetteville, AR 72701, United States.

\author{
Article Details \\ Article Type: Expert Opinion \\ Received date: $05^{\text {th }}$ October, 2019 \\ Accepted date: $12^{\text {th }}$ November, 2019 \\ Published date: $14^{\text {th }}$ November, 2019
}

"Corresponding Author: Johanna Thomas, Associate Professor, School of Social Work, University of Arkansas, 112 W. Center St., Room 408, Fayetteville, AR 72701, United States. E-mail: johannat@uark.edu

Citation: Thomas J, Deckert JC, Thomas S (2019) The Be SMART Initiative: Educating Communities on Safe Gun Practices. J Pub Health Issue Pract 3: 150. doi: https://doi.org/10.33790/jphip1100150.

Copyright: $\left({ }^{2} 2019\right.$, This is an open-access article distributed under the terms of the Creative Commons Attribution License 4.0, which permits unrestricted use, distribution, and reproduction in any medium, provided the original author and source are credited.

\section{Abstract}

Gun violence is a growing public health crisis in America. Approximately 1,500 children per year die from gun violence in the United States. Approximately 800 children are shot and killed, another 600 die by gun suicide and 100 shoot themselves or someone else because of improperly stored firearms [1-3]. This manuscript highlights the need for social workers and allied health professionals to play a key role in preventing intentional and unintentional child shootings by educating clients and communities about safe gun practices. This manuscript describes the "Be SMART for Kids" program, a strengths-based, empowerment model with a nonconfrontational approach to talking about guns and gun safety. Practical information for implementing the Be SMART model by incorporating it into everyday conversations, public health practices, education and policy are also described.

Keywords: Gun Violence, Gun Safety, Unintentional Child Shooting, Social Work

\section{Introduction}

There is an abundance of evidence to suggest a serious and immediate need for effective strategies to reduce all forms of gun violence, including mass shootings, "urban gun violence", suicide, and unintentional child shootings. Gun violence has become a public health crisis with more than100people being shot and killed every dayin the U.S. and hundreds more injured [3] of those gun violence deaths, children are arguably the most vulnerable victims. Firearms are the 2nd leading cause of death for all children in the U.S. and the leading cause of death for Black children. In the U.S., nearly 1,500 children under the age of 18 are killed with guns every year. Annually,about 800 children are victims of homicides committed with a firearm [2], another 600 children die ingun related suicides [3], and approximately 100 children are killed unintentionally every year with a firearm [3]. To put these statistics into international perspective, childrenin the U.S. are 11 times more likely than their peers in other developed countries to die by gun violence $[2,4]$. In fact, recent statistics indicate more than $90 \%$ of all children under age 14 who are killed by guns in high-income countries, are killed in the U.S [5]. New research indicates much of the harm caused by firearmsis potentially preventable as nearly 4.6 million children live in homes whereguns are improperly stored, meaning they are both loaded and unlocked [6].

The risk of death when a gun is left unsecured is equivalent to the risk posed by unsecured prescription medications, household chemicals, and unlocked swimming pools [7]. Although school and mass shootings are more likely to make national news headlines, the reality is that for children under the age of 13, a gun homicide most frequently occurs in the home [4]. A recent study found that nearly $90 \%$ off all child involved unintentional shootings, for both injury and death, occur in the home [8]. Moreover, easy access to firearms facilitates urban gun violence considering some youth access unsecured firearmsin their household and carry them out of personal fear, which facilitates the cycle of violence $[9,10]$. Further, in incidents of gunfire on school grounds, $78 \%$ of shooters under the age of 18 illegally obtained their firearms from their home or the home of a friend [11].

The headlines from across the country speak to the public health crisis of unsecured firearms. In January of 2018, there was a school shooting at Marshall County High Schoolin Kentucky in which 16 people were shot and wounded. The 16-year-old shooter had gained access to his stepfather's unsecured pistol from his bedroom [12]. In May of 2018 a 4-year-old boy fromLouisa, Virginia unintentionally shot his 2-year-old brother, Tyson, after accessing an unsecured gun that was kept 'high in an upper cabinet' [13]. Related to urban gun violence, a17-year-old from Jackson, Mississippi, told the Jackson Free Press [9] that some young peoplein his community carry guns out of fear of being robbed or shot, and believe that having a gun will allow them to defend themselves. Finally, a 13-year-old from Brewster, New York who was a friendly and popular 8th-grader came home from school one day in January of 2013 and took one of his father'sunlocked, loaded guns and shot himself. This young man's family does not believe he planned todie that day but easy access to a loaded gun and an impulsive decision led to a fatal tragedy [14]. All four of these stories demonstrate the potential fallout resulting from young people having access to unsecured guns. None of the aforementioned stories are quite the same, but all are tragic, and each of them was preventable.

Gun violence has become a public health crisis,however, there are promising research based best practices that may prevent many of these deaths. Social workers are widely recognized for their contributions toward improving the nations' health by providing much needed social services as well as identifying and addressing the social determinates of health [15]. There are more than 680,000 social workers in the U.S. and employment in the sector is expected to grow by $11 \%$ in the next decade [16]. 
For comparison, there are approximately 670,000 full time sworn law enforcement officers in the U.S. [17]. Based on both their ubiquity and expertise, it is imperative that social work professionals take the lead on educating individuals, families, agencies, and communities on the dangers of unsecured firearmsso as to stymie the epidemic of gun injuries and deaths among American youth [18]. This manuscript examines the role of social workers and allied helping professionals in educating clients, agencies, and communities about gun safety. We describe a new, research-based, best practices curriculum, the Be SMART for Kids program [19], which is aimed at reducing unintentional child shootings through education and action. This program places the onus of gun safety on adults as opposed to programs tailored toward children, particularly boys, (i.e. Eddie Eagle Program sponsored by the National Rifle Association) which do not reduce the likelihood of a child handling a gun when unsupervised [20]. Finally, we provide an overview of the implications for practice, education, and policy.

\section{Review of the Literature}

After the tragedy at Sandy Hook Elementary in Newtown Connecticut in 2012 in which 20 children and six educators were gunned down in their classroom, Google searches related to gun purchases increased four times the normal rate [21]. During this time, gun sales increased by an estimated three million purchases. As the number of firearm purchases increased so did unintentional shootings [21]. Moreover, these deaths were concentrated in states with the largest per capita gun sales post Sandy Hook prompting a new wave of research on the accessibility of firearms for children in their homes. Researchers surveyed parents in the waiting rooms of pediatrician's offices in Missouri and Illinois and found that among the 1,246 participants interviewed, 36\% reported that they kept guns in the house [22]. Among respondents who indicated thatfirearms were present in their home, $66 \%$ reported thatthere was more than one gun present in the residence [22]. In another study, $85 \%$ of gun owning parents admitted they were not practicing safe storage with their firearms and nearly three quarters (72\%) of parents believed their child would be able to differentiate between a real and fake gun [20]. When children wereasked about guns in their home more than $70 \%$ knew where they were stored [23]. Children are naturally curious about guns and exposure to guns in the home and the media heightens this interest, as well as their acted-out aggression in play [24].

Gun violence is omnipresent in American society as indicated by a recent study on the prevalence of gun violence within personal networks, which reported that the lifetime likelihood of knowing a victim of gun violence within any given personal network is $99.85 \%$ [25]. These overall statistics obscure important racial disparities as Blacks have the highest probability at $99.9 \%$, followed by Hispanics $(99.5 \%)$, Non-Hispanic whites, $(97.1 \%)$ and other racial groups $(88.9 \%$;) [25]. The likelihood of knowing someone within their personal network who died from a gun violence incident is slightly smallerat $84.3 \%$. Again, Blacks have the greatest likelihood of knowing someone who died as a result of gun violence $(95.5 \%)$, followed by Non- Hispanic whites $(85.3 \%)$, Hispanics $(62.4 \%)$ and other racial groups $(46.7 \%)$. Black youth have the highest rate of gun related homicide while white and Native American children have the highest rate of gun suicide [2]. Although there is some evidence that white men are most likely to own guns, Black individuals are the most likely to die from guns [26]. Boys are disproportionately affected by gun violence as they are responsible for approximately $82 \%$ of gun-related deaths and $84 \%$ of gun related injuries [2].

The gun violence epidemic is both a public health crisis and a social justice issue based on frequency of occurrence, the mental and physical toll, and the fact that marginalized populations are disproportionatelyimpacted [26]. However, information on the role of social workers and other helping professionalsin gun safety is sparse

J Pub Health Issue Pract

Volume 3. 2019. 150 within the extant literature. Moreover, the limited literaturethat is available is primarily focused on social workers arming themselves while on home visits or in other potentially dangerous scenarios [27]. Research pertaining to how, or if,social workers assess for gun safetyis nearly non-existent. Slovak et al. [28] surveyed 697 social workers in Ohio and found the vast majority did not assess for or educate clients on gun safety. Social workers reported a number of reasons for not talking about gun safety with their clients including: lack of training on the risks; lack of risk awareness around gun safety; discomfort with the topic; they did not feel it was their responsibility; they lacked the time necessary to talk about it; they felt they had more important or pressing issues to discuss and; they had concerns about how to talk about guns when troubling information was discovered. On the other hand, social workers that reported assessing for guns in the home and gun safety measures reported having previous firearm training, felt influenced by the media to ask, or asked out of necessity with a depressed or suicidal client [28].

Although unintentional gun deaths are growing at an alarming rate and more than 4.6 million children live in homes with unsecured weapons, neither social work nor allied health professions have addressed this issue [29]. In the current landscape, most of the political and social discourse concerning firearms has centered on gun laws, constitutional rights, and unfettered access to guns, ammunition, and firearm accessories. Because of this, the focus on firearm safety, the means by which guns should be secured in order to prevent access to children, and unintentional death and injury,have been neglected [26]. Social workers have been hesitant to address gun violence because of both the implied politics that come with conversations about guns and because of a lack of education and confidence.In an effort to address this deficiency in the literature and in practice, this manuscript describes a curriculum developed for use by social workers, allied health professionals, and other key community stakeholders. The purposeof the curriculum is to educate clients and communities on the dangers of improperly stored weapons and unintentional child shootings.

\section{Social Workers, Public Health Issues, and Gun Violence Prevention}

Social workers understand how to work within the micro, mezzo, and macro systems, all of which are necessary and relevant to understanding public health issues [18]. Historically, the social work profession has been at the forefront of public health issues that are both controversial and political in nature, such as comprehensive sex education, HIV/AIDS, nutrition and weight management, disease management, and substance abuse intervention. The social work profession is also concerned with social justice [30]. Not only do social workers have a long history of working on public health issues they have considerable access to marginalized and at-risk client populations, client homes, and possibly more gun owners than many other health professionals. These factors, in addition to the sheer number of social workers (over 680,000) in the U.S. and the number of families with which they work, suggest that social workers are uniquely situated to advocate for gun safety and gun violence prevention [18]. Moreover, social workersoften meet with clients in their homes as school based social workers, home health providers, early interventionists, health and nutrition educators, and child welfare workers. Social workers educate individuals, families, agencies and communities on safety issues as part of their everyday work duties. They also facilitate safe spaces for education and learning, especially for difficult or controversial topics. Further, social workers are brokers of needed resources when working as community change agents and they understand the most effective ways to address community safety [30].

The core of the social work profession is public safety, and at the heart of that is keeping clients and communities safe [30]. Social workers are trained to work collaboratively across disciplines with 
other health professionals. Although social workersoften deal with the aftermath (e.g., trauma, healing, and grief) of unintentional shootings, homicides, and suicides, little has been done to address this issue proactively. Although no single profession has taken on the responsibility of educating the public about responsible gun ownership, gun safety, and gun violence prevention, allied health professions are being urged to assess for the availability of firearms $[31,32]$. However, much like social work, allied health professionals are primarily advocating for firearm removal when warranted,such as with a suicidal or homicidal client or in a domestic violence situation [31]. Although firearm removal may be ideal in some situations, this strategy overlooks more feasible interventions that allow for gun ownership while maintaining higher standards of safety. Gun safety is not just for clients with suicidal ideation. Assessing for firearms and proper gun storage is imperative when there is a young child in the household, an elderly person with cognitive impairments, or even a teenager who has a history of violence or aggression [33].

Part of social work education is ensuring professionals in the field are both trained and practiced in talking about difficult or sensitive issues. In fact, practitioners do this all the time when addressing relationships (e.g., marital counseling and mediation), sexual orientation or gender preference, domestic and child abuse, rape and other forms of sexual assault, and even death and dying. Further, social workers already have the necessary skill set to address determinants of diverse public health crises, including gun safety $[15,30]$. Mental health professionals are trained to be critical consumers of research, advocate for clients and communities, and assist clients with reducing risky behaviors [30].

\section{The Be SMART for Kids Program}

The Be SMART for Kids program was developed by the organization "Moms Demand Action for Gun Sense in America" in 2015 in order to bring together parents and adults concerned about children, guns, and safety [19]. Since the program was first introduced four years ago, the scope has slowly evolved to include not just parents, but also teachers, health and mental health professionals, and community stakeholders. The core of the program rests on the premise that the vast majority of people want children to grow up happy and healthy and that the onus of safety is on the adult, not the child [19]. The program acknowledges the rights of individuals to make responsible decisions about how to protect their homes, families, and communities, including owning firearms and having them in homes. The Be SMART for Kids framework is used to teach parents and other adults how toprotect children from gun violence with simple, easy to remember behaviors. Outlined below are the five pillars of the program that coincide with the SMART acronym: $\mathrm{S}$ stands for securing all guns in your home and vehicles; M stands for modeling responsible behavior around guns; A stands for Asking about the presence of unsecured guns in other homes; R stands for recognizing the role of guns in suicide; $\mathrm{T}$ stands for telling your peers to be SMART

\section{S - Appropriately Secure all guns in your home and vehicles}

More than 13 million households in the U.S. have at least one child and one gun present and there is both empirical and anecdotal evidence indicating the majority of children in gun-owning households know where the gun is stored [6,34]. A critical question is therefore what are the best practices for securing firearms in the home? Securing guns locked and unloaded with the ammunition stored separately is the single most important step that can be taken to prevent unintentional gun violence [19]. Hiding a gun is not the same as "securing" a gun and strategies such as this have a high potential of leading to tragedy. For example, recently a 4-year-old Virginia boy unintentionally shot his 2-year-old brother after accessing an unsecured gun that was stored 'high in an uppercabinet'. In incidents of gunfire on school grounds, the majority of shooters under the age

J Pub Health Issue Pract

Volume 3. 2019. 150 of 18 obtained the gun(s) from their home or the homes of relatives or friends [11]. The accessibility of firearms in the home, the natural curiosity of youth, and even complicated safety reasons that push some teens to want a gun, such as personal safety concerns, set a potentially deadly backdrop. As such, the onus and responsibility to prevent easy accessto guns falls entirely on adults.

Research also finds that responsible gun storage is associated with a decreased risk of firearm suicide and unintentional firearm injury among children. Grossman et al. [35] demonstrated that households in which both firearms and ammunition were secured in a locked fashion had a $78 \%$ lower risk of self-inflicted firearm injuries among children and teenagers and an $85 \%$ lower risk of unintentional firearm injuries. Some commonly used responsible storage practices include using a cable lock, lockbox, firearm safe, and storing firearms unloaded with ammunition stored separately. Properly securing firearms also limits the likelihood that a gun will be stolen. This is a critical consideration considering that stolen firearms become part of the cadre of illegal firearms available in a community and are a significant predictor of crime levels in the community at-large [10,36]. A staggering number of guns, approximately 380,000 , are stolen each year from private gun owners [37]. Further, current research indicates gun owners are three times more likely to have a gun stolen if they carried a gun in the last month [37]. Research also indicates nearly one-quarter of stolen guns are taken from cars [36]. Again, simply hiding or storing a gun on a high shelf, a glove compartment, or underneath a car seat is not commensurate with responsible storage [34].

Adults should not expect that children will simply not find or touch an unsecured gun [35]. Children are naturally inclined to be observers and explorers [38]. Research in child development finds that children are especially curious about items deemed forbidden or off limits. In fact, one study of 300 children in rural Alabama reported that over $70 \%$ of children in households in which a gun was present knew where the gun was stored and $36 \%$ of those children admitted to handling the gun without supervision [34]. As such, it is critical that gun owners store weapons appropriately and that young people are taught to understand the safety measures that must be taken when a gun is found and an adult is not present. Young children in particular do not generally have an accurate concept of death or its permanence [38]. Children tend to be confused about the permanency of death and, when probed, young children often report that a person who has died is sleeping or is coming back [38]. The understanding of death varies across children, grows with the child through time or experienced loss, and even then, may be more limited than it appears.

It is also important to consider the physical abilities of children, which are often difficult to gauge. An adult may assume a child cannot reach an unsecured weapon at the top of a closet or dresser or that the child is too weak to hold or fire the gun [39]. However, research indicates children as young as two are able to both handle and fire a gun [39]. For households in which guns are present, proper storage is paramount to safety. Guns, real and toy, can appear very similar making it difficult for a child to distinguish the difference. As such, every gun should be treated as if it is real and loaded. In addition to securing weapons it is important that adults tell children to follow these safety rules: a) never touch a gun they find or allow a friend to touch a gun, b) leave the area immediately, and c) find an adult [40].

\section{M - Model Responsible Behavior Around Guns}

Every law-abiding adult has the right to decide whether or not to have a gun in the home. Butit is irresponsible and dangerous to ignore the curiosity of children and simply relying on kids not finding an unsecured gun in their home or that of a friend or family member. Again, a third of youth report handling guns that are present in their home, many doing sowithout the knowledge of an adult [34]. Nearly a quarter of parents didnot know that their children had handled the gun in their house.It is always an adult's responsibility to prevent unauthorized 
access toguns, not a child's responsibility to avoid guns. All parents, regardless of having a firearm in their home, have a responsibility to talk to their kids about gun safety. This is a critical precaution; however, it is not a guarantee of safety. One study found that young children who go through a week-long gun safety training are just as likely as children with no training to approach or playwith a handgun when they find one [41].

The right to decide to have firearms in the home must be conceptualized as coming with the critical duty of modeling responsible behavior around children and others [19]. The NSSF [40], an organization representing gun owners, recommends the following questions be asked before deciding to purchase a firearm that will be kept in the home: a) do all of the adults in the household support having a gun in the home? b) do all of the adults in the home agree to participate in firearm training? c) are there any risk factors present that should be considered before bringing a gun into the home? and d) what precautions will be taken to ensure children are protected? The NSSF [40] also recommendsa host of safety precautions that should be modeled when handling a firearm, including: a)the gun is always pointed in a safe direction (down); b) all guns are treated as if they are loaded and ready to fire; c) the person handling the firearm knows what the target is and what is behind and beyond the target; and d) fingers are kept off the trigger until ready to fire and that the person handling the firearm does not rely on the gun's safety mechanism. Modeling responsible behavior means that SMART adults do their part to curtail the accessibility of firearms to children. Parents and caretakers must also recognize thatit is impossible to fully control the environment that their child is in at all times. As such, it is imperative to teach children not to touch a gun if they come across one, real or toy, provide them with the tools to get out of a dangerous situation, and to alert an adult. As such, adults are responsible for modeling safe firearm behavior and to prevent kids from getting into a dangerous situation.

\section{A- Ask About the Presence of Unsecured Guns in Other Homes}

It is common for individuals, even health professionals, to shy away from asking about the presence of firearms in other people's homes or vehicles. People often cite awkwardness or discomfort as part of the reason they do not ask about guns in other homes before their child spends time there. Many others likely believe that people they know properly secure their firearms or they simply do not think about the magnitude of the risk to which children may inadvertently be exposed. Such inaction is not acceptable as asking about the presence of firearms in someone's home in which children will spend time should be as natural as asking about any other safety issue. It is commonplace to ask questions about safety concerns such as where and how chemicals and medications are stored, if there is a lock on the pool gate and if the pool has an alarm, or even if pets are child safe [19]. Normalizing inquiries as to the presence of guns in the household and measures taken tokeep children safe is another critical step to reducing the risk of an unintentional shooting.

It is recommended that parents and adults ask about guns in other up front in an effort to normalize such conversations [19]. In addition to homes and vehicles, parents and caregivers should inquire about guns in home daycares and any other placeschildrenmay spend time. Again, approximately 4.6 million childrenreside in a householdwith at least one loaded and unlocked gun [6,42]. As such, it is critical to ask about firearms in any home, vehicle, and venue childrenmay visit.Although asking about guns in the home may at firstseem awkward,normalizing such inquires may be facilitated by making it part of a general safety conversation that touches on a variety of concerns (e.g., pets, pools, medications, allergens, alcohol, media/ videos) or asking such questions via email or text.

\section{R - Recognize the Role of Guns in Suicide}

The presence of an unsecured firearm is an acute risk factor for gun people's homes and also offer this information about their own home

suicide [19]. Discussions of guns and gun violence often divert to the topic of homicides, however, suicides committed with a gun are an equally pressing public safety concern. In fact, similar to most violent crimes, homicide rates among children declined from 2007 to 2014 while suicide rates rose by $60 \%$ [22]. Current research indicates the availability of a gun is a more influential predictor of suicide than an underlying psychiatric disorder [43]. The method by which a person attempts suicide is an important consideration. Approximately $40 \%$ of child suicides involve a gun [1]. Most people who attempt suicide do not die - unless they use a gun [11]. Guns are the most lethal method for suicide with $85 \%$ of gun related suicide attempts resulting in death compared to $<5 \%$ of attempts using all other methods [44].

Recognizing that a loved one is in distress should lead responsible gun owners to considerat least temporarily removing a gun from their home. Such reflections should be viewed as relevant by all parents and gun owners considering results from the National Youth Survey indicate that $17 \%$ of high school students have seriously considered attempting suicide within the last year [45]. Another study demonstrated that $41 \%$ of adolescents in gun-owning households report having "easy access" to the guns in their home [46], as many as $33 \%$ of youth have reported handling their parents' guns, and $25 \%$ of parents didnot know that their children had handled the gun in their house [34].

Some teens do exhibit suicidal ideation warning signs. A recent study found that among children who completed suicide, approximately $33 \%$ were depressed before death and another $25 \%$ had been clinically diagnosed with a mental health problem [22]. General suicide risk factors for teens include a change in mood or behavior, talking about wanting to kill themselves or making statements about their family or friends being better off without them, an increase in aggression, or feeling hopeless, ashamed or desperate [33]. Suicide is often an impulsive act and people who survive a suicide attempt are unlikely to try again. Underscoring the link between guns and suicide, the extant literature consistently reports a strong connection between availability and access to guns and suicides committed with a gun. In fact, suicides committed with a gun are viewed as the most accurate and readily available proxy measure of access to firearms in communities across the U.S. [47].

Exemplifying how the recommendations of the Be SMART program are interrelated, recognizing the role of guns in suicide is an important factor underscoring the importance of proper storage and yet another rationale for normalizing discussions of access to guns in homes and vehicles. Reduced access to firearms, whether that means they are not present or responsible storage methods are employed, is associated with a decreased risk of child firearm suicide [43]. As children growolder, parents mustalso reassess their storage methods. A simple cable lock may no longer be sufficient when older and more resourceful children are present and a gun safe may be the best option for keeping one's family and children safe. Such assessments and decisions should be as common place as safety devices on vehicles for young drivers, building fences around homes and pools, and upgrading home security equipment.

\section{T - Tell your peers to be SMART}

The final pillar of the Be SMART for Kids program is teaching others about gun safety [19]. Teaching others includes making sure that gun safety is an open and normalized dialogue, particularly regarding proper storage, and especiallyin conversations withgun owners.Part of telling others about gun safety means the conversation is used to alleviate the politics and fear that surrounds firearms. Telling others about gun safety should not become a debate on the availability of firearms in society at-large but rather a conversation about safety, an issue in which the vast majority of adults believe. In order to make real progress toward ending gun violence in all its forms, gun safety must become a truly non-partisan issue centered on the importance of public safety.

J Pub Health Issue Pract

Volume 3. 2019. 150
JPHIP, an open access journal ISSN- 2581-7264 
Since the inception of Be SMART, in May of 2015, almost 3,000 volunteers (e.g. parents, grandparents, teachers, doctors, social workers) have been trained to deliver the Be SMART message at community presentations, tabling events, churches, social work continuing education events, and other venues. The program has also been presented at a variety of state and national academic and professional conferences as well asfor the National Association of Chiefs of Police, Safe Kids Worldwide, the American Medical Student Association, Rotary Club and PTA meetings, in personal homes, and doctor's offices [19]. In fact, over 2,000 events have been held in 43 states. In order to continue to effectively disseminate information on gun safety and implore all individuals to take responsibility for ensuring the safety of all children it is imperative that the Be SMART message be distributed as widely as possible and to diverse groups and regions.

Research demonstrates that law enforcement, the military, and hunting or outdoor groups are particularly effective at communicating safe storage practices [19]. The teaching aspect of being SMART is powerful. A common response from past Be SMART participants is that individuals they talk to about proper gun safety respond in a positive manner [19]. As a direct result of Be SMART, these individuals know to Askabout the presence of guns before their children go to other people'shomes, they have talked to family members about guns in the homes when they have Recognized the role of guns in suicide, and gun owners are Modeling responsible behavior. The question asked of all Be SMART trainees and the question they ask others is "who are you going to tell to Be SMART today?".

\section{Implementing the Be SMART for Kids Model into Social Work Practice}

The extant literature indicates that engaging clients in discussions about gun safety and storage continues to be an uncomfortable topic for health professionals [8]. Historically, conversations around guns have been steeped in political debate. Little work has been done to remove the politics and focus on safety, a truly non-partisan issue. In an effort to remedy this situation, it is recommended that health professionals, including social workers, learn about firearms in the same manner they have learned about other public safety issues, through research and experience. As suggested by the NSSF [40], visiting a gun range orattending a gun safety class allows individuals and practitioners to become familiar with different firearms and ammunition. These venues also allow one to become familiar with "gun culture" as well as perceptions of gun owners [48]. Individual social work practitioners may or may not have differing views than their clients concerning a number of aspects related to guns;however, the ultimate goal of education and intervention is ensuring clients, their families, and their communities are free from gun violence in all its forms. As such, it is imperative that social workers and allied health professionals begin integrating gun safety into conversations with clients. Moreover, to facilitate the dissemination of the SMART message and general information on gun safety social work agencies and therapist's offices should provide gun safety literature in waiting rooms, new patient packets, or with other information provided to clients.

The Be SMART for Kids program is a strengths-based, empowerment model with a non-confrontational approach to talking about guns and gun safety.When implementing the SMART components and integrating the pillars of the program into practice there are general recommended guidelines for engaging clients about gun safety. First, avoiding confrontational dialogue is of utmost importance [27]. Most gun owners are knowledgeable about guns and committed to gun safety and should be approached in this manner. The vast majority of parents, adults, and gun owners want to keep children and families safe from unintentional firearm injuries and death. It is up to the provider to give the context for questions pertaining to firearms when asking. The provider must strive to understand the client's fears about having their weapons or their children removed from the home [27]. Many gun owners also fear having their firearms and ammunition inaccessible, as they perceive they may need it in a moment's notice. As such, mental health professionals must be knowledgeable about gun laws and proper storage solutions for the variety of firearms they are likely to encounter so as to maintain their role as the expert and effectively alleviate their client's fears [27]. As social workers, the focus of the interaction should remain on physical and mental health outcomes as opposed to political and ideological arguments.

It is recommended that assessing for firearms should be integrated into the regular assessment material used by practitioners and agencies. As part of this assessment, social workers should ask about gun safety in the primary home as well as anywhere else the child spends or is likely to spend time. After completing the assessment, an intervention, if necessary, should be provided. This intervention could range from providing the client with educational materials to discussing proper gun storage, supplying gunlocks, or helping a client select an appropriate gun safe. Regardless of whether the client is a gun owner, part of the intervention strategy should include educating clients on asking others about unsecured guns in their homes or anywhere the child may spend time. As with any uncomfortable situation, using role-play activities with clients is a proven way to build the confidence necessary for asking about firearms [49]. Some clients may be more comfortable talking about firearms through text message or e-mail, so pre-made scripts may be provided.

For clients who own guns, blanket recommendations are not viable as each client's situation and firearm areunique. Instead, social workers should employ an empowerment approach that allows clients to keep their homes and families safe while also protecting their families. As such, it is imperative that social workers ask how and where the client stores their firearm and are capable of identifying safe storage alternatives. As such, practitioners must become familiar with diverse firearms, firearm storage solutions and how and where to obtain safety and storage devices (free and otherwise) if the agency or practitioner is not providing gunlocks or safes.

It is important to recognize that gun safety goes beyond individuals and although making a single home safe may mean the difference between life and death for a child, this is only one aspect of addressing the larger public health crisis. Social workers should strive to provide firearm safety education to the greater community, assist communities with civic engagement, and engender greater participation in the gun violence prevention movement [18]. Extensive swaths of marginalized and under-served communities are disproportionately affected by gun violence [25]. These communities should be viewed as allies and empowered to participate in gun violence prevention efforts. As with any community change model, social work professionals and community organizers must provide the tools communities need to apply pressure on government entities to keep children safe [18].

\section{Implications for Social Work Education and Policy}

It would behoove public health professionals to use the Be SMART for Kids model to not only educate clients about gun safety but also educate social work students and allied health professionals. Changing the conversation around guns means changing how students and professionals talk about guns and gun violence. Although firearms are often a volatile issue andengender a political ideological debate, the fact remains thatthe vast majority of adults want children to survive to adulthood and to be healthy and happy. As such, conceptualizing gun safety as a non-partisan public health issue and teaching students and professionals to do the same will allow for more straightforward and productive conversations with clients, agencies, and communities.

Although social workers have long been viewed as serving a critical role in improving diverse health outcomes and they are uniquely 
situated to administer the Be SMART program, social work practitioners, educators and agencies must first learn to be comfortable with guns and gun safety, regardless of their personal beliefs. This entails empowering students and other professionals to take a gun safety course, to become familiar with firearms and storage, and to have the ability to assist clients with appropriately securing their firearms [28]. The fact remains that students and working professionals must understand that the onus of keeping children safe falls entirely on the shoulders of all adults, not just parents and caregivers. Advocating for gun safety should also include a push forpolicy changes at the agency level. Many human service agencies are not currently addressing gun safety. As such, more agencies should create policies that explicitly allow practitioners to educate clients on gun safety, assess for gun safety, and implement interventions when needed. Agencies should also move to make gun safety materials, such as Be SMART for Kids, available to clients in waiting rooms and in new patient packets. Lastly, social work and allied health professionals should continue to advocate for policy and law changes at the local, state, and national level, to keep communities safe from gun violence.

\section{Conclusion}

The Be SMART for Kids program is a strengths-based, empowerment model with a non-confrontational, non-partisan approach to talking about guns and gun safety that allows both the practitioner and client a safe space in which to have open conversations without fear of personal or political backlash. Even if a client refuses to answer questions immediately about firearmsin their own home, they may be open to talking about guns and gun safety concerns they have or should have pertaining to other places their children spend time. Feedback from individuals who have learned about gun safety through Be SMART indicates they now recognizethe importance of asking about the presence of guns in other people's homes, have talked to family members about guns in homes and vehicles, recognizethe risk associated with firearms and gun suicide and spread that message, and gun owners are modeling responsible behavior as a direct result of Be SMART [19]. Although the Be SMART model will not save every life,we have a responsibility as public health professionals to take action to prevent as many deaths as possible and implementing this model is a simple and reasonable action we can take.

Going forward, as the Be SMART programs gains wider acceptance and continues to be implemented in diverse areas and among diverse populations it will critical that researchers design and implement studies capable of empirically assessing the efficacy of the Be SMART pillars. The Be SMART program was developed based on empirical research and the recommendations advocated for in the program are evidenced based. Although the program is grounded in current research-based best practices, there is a critical need to evaluate the effectiveness of the program messages and strategies so that it can be truly evidence based. The efficacy of the Be SMART program must be evaluated so as to empirically establish the effectiveness of the program. Specifically, future research should assess how social workers are implementing the program in practice, whether the personal beliefs and comfort of social workers influences the effectiveness of the program, and of course whether and how the program may be influencing beliefs about and comfort with firearms, where and how individuals store their weapons, when and how people ask about firearms, and eventually, whether the program is associated with a reduction in gun violence. Such research will be critical to the continued refinement of the Be SMART program and establishing that the program is evidenced-based may open additional avenues of funding geared toward both supporting the continued training of social workers to administer the program and implementing the program within diverse communities. Social workers are uniquely situated to address the epidemic of gun violence in the U.S. based on their ubiquity, their expertise in addressing the social determinants of public health outcomes, and the breadth of families with which they work. Establishing the efficacy of the Be SMART program will allow them the confidence to administer the program and continue their leadership in educating individuals, families, agencies, and communities on the dangers of unsecured firearms so as to stymie the epidemic of gun injuries and deaths among American youth.

\section{References}

1. Centers for Disease Control and Prevention. National Centers for Injury Prevention and Control, Web-based Injury Statistics Query and Reporting System (WISQARS) Fatal Injury Reports. (2018a) Data from 2017. Children aged 1 to 17, Black defined as non-Hispanic, number of deaths by known intent (homicide, suicide, unintentional deaths). Age 0 to 1 calculated separately by the CDC because leading causes of death for newborns and infants are specific to the age group.

2. Centers for Disease Control and Prevention. National Centers for Injury Prevention and Control, Web-based Injury Statistics Query and Reporting System (WISQARS) Fatal Injury Reports. (2018b). A yearly average was developed using five years of most recent available data: 2013 to 2017. Analysis includes children aged 0 to 17 , homicide includes legal intervention.

3. Centers for Disease Control and Prevention. National Centers for Injury Prevention and Control, Web-based Injury Statistics Query and Reporting System (WISQARS) Fatal Injury Reports (2018c). A yearly average was developed using five years of most recent available data: 2013 to 2017. Analysis includes children aged 0 to 17 .

4. Fowler KA, Dahlberg LL, Haileyesus T, Gutierrez C, Bacon S (2017) Childhood firearm injuries in the United States. Pediatrics 140: 1-13.

5. Grinshteyn E, Hemenway D (2016) Violent death rate: The US compared with other high-income OECD countries, 2010. Am J Med 129: 266-273.

6. Azrael D, Cohen J, Salhi C, Miller M (2018) Firearm storage in gun-owning households with children: Results of a 2015 national survey. J Urban Health 95: 295-304.

7. Williams J (2006) More teens are involved in accidental gun deaths. Miami Times, 4C.

8. Li G, Baker SP, Discala C, Fowler C, Ling J et al. (1996) Factors associated with the intent of firearm-related injuries in pediatric trauma patients. Arch Pediatr Adolescent Med 1160-1162.

9. Jackson Free Press (2016) A hunger to Live: The Struggle to Interrupt the Cycle of Violence.

10. Yu SV, Lee D, Pizarro JM (unpublished) Illegal Firearm Availability and Violence: Neighborhood-Level Analysis. J Interpersonal Violence, online first.

11. Everytown for Gun Safety (2018a). Disrupting Access: Addressing Firearm Suicide in the U.S.

12. NBC (2018) Kentucky High School Shooting: Two Dead after Attack at Marshall County High School.

13. Miami Herald (2018) 4-year-old Thought Gun was a Toy. Now His Little Brother is Dead, Virginia Cops Say.

14. USA Today (2014) Dad Gets 5 Years Probation for Gun Son Used in Suicide.

15. National Academies of Sciences, Engineering, and Medicine. (2019) Integrating Social Care into the Delivery of Health Care: Moving Upstream to Improve the Nation's Health. Washington, DC: The National Academies Press.

16. United States Bureau of Labor Statistics (2019) Social Workers: Occupational Outlook Handbook.

17. United States Department of Justice, Federal Bureau of Investigation (2018) Crime in the United States, 
18. Meinert M (2016) Social work dives deep into gun violence as a public health issue.

19. "Be SMART for kids" (2019) http://besmartforkids.org/

20. Holly C, Porter S, Kamienski M, Lim A (2018) School-based and community-based gun safety educational strategies for injury prevention. Health Promotion Practice.

21. Levine PB, McKnight R (2017) Firearms and accidental deaths: Evidence from the aftermath of the Sandy Hook school shooting. Science 358: 1324-1328.

22. Garbutt JM, Bobenhouse N, Dodd S, Sterkell R, Strunk RC et al. (2016) What are parents willing to discuss with their pediatrician about firearm safety? A parental survey. J Pediatr 179: 166-171.

23. Everytown for Gun Safety (2014) Innocents lost: A year of unintentional child gun deaths.

24. Dillon KP, Bushman BJ (2017) Effects of exposure to gun violence in movies on children's interest in real guns. JAMA Pediatr 171: 1057-1062.

25. Kalesan B, Weinberg J, Galea S (2016) Gun violence in Americans' social network during their lifetime. Preventative Med 93: 53-56.

26. Cook PJ, Pollack HA (2017) Reducing access to guns by violent offenders. Russell Sage Foundation J Soc Sciences 3: 2-36.

27. Children's Services Practice Notes (2016) Guns in the home: Considerations for worker safety. N.C. Division of Social Services and the Family and Children's Resource Center.

28. Slovak K, Brewer TW, Carlson K (2008) Client firearm assessment and safety counseling: The role of social workers. Soc Work 53: 358-366.

29. Roszko PJD, Ameli J, Carter PM, Cunningham RM, Ranney, ML (2016) Clinician attitudes, screening practice, and interventions to reduce firearm related injury. Epidemiological Rev 38: 87-110.

30. National Association of Social Workers (NASW; 2017) Code of Ethics of the National Association of Social Workers.

31. Hamblin J (2014) The Questions Doctors Can't Ask. The Atlantic.

32. Shroeder MO (2017) A Prescription for Gun Safety. U.S. News \& World Report: Health.

33. Siu AL (2016) Screening for depression in children and adolescents: US Preventive Services Task Force recommendation statement. Pediatr 137: 1-8.

34. Baxley F, Miller M (2006) Parental misconceptions about children and firearms. Arch Pediatr Adolescent Med 160: 54247.

35. Grossman DC, Mueller BA, Riedy C (2005) Gun storage practices and risk of youth suicide and unintentional firearm injuries. JAMA 293: 707-714.

36. Stolzenberg L, D'Alessia SJ (2000) Gun availability and violent crime: New evidence from National Incident-Based Reporting System. Social Forces 78: 1461-1482.

37. Hemenway D, Azrael D, Miller M (2017) Whose guns are stolen? The epidemiology of gun theft victims. Inj Epidemiology 4: 11.

38. Erdman S (2018) Promoting gun safety: Sharing knowledge of child development to support informed decisions. NAEYC 73.

39. Naureckas SM, Galanter C, Naureckas ET, Donovan M, Christoffel KK (1995) Children's and women's abilities to fire handguns. Arch Pediatr Adolescent Med 149: 1318-22.

40. National Shooting Sports Foundation (NSSF; 2018). Welcome to the Own It? Respect It.
41. Hardy MS (2002) Teaching firearm safety to children: Failure of a program. J Dev Behav Pediatr 23: 71-76.

42. Azrael D, Cook PJ, Miller M (2004) State and local prevalence of firearms ownership measurement, structure, and trends. J Quant Criminol 20: 43-62.

43. Anglemyer A, Horvath T, Rutherford G. (2014) The accessibility of firearms and risk for suicide and homicide victimization among household members: A systematic review and meta analysis. Annals Internal Med 160: 101-110.

44. Miller M, Azrael D, Barber C (2012) Suicide mortality in the United States: The importance of attending to method in understanding population-level disparities in the burden of suicide. Annual Rev Pub Health 33: 393-408.

45. Kann L, McManus T, Harris WA, Shanklin SL, Flint KH et al. (2018) Youth risk behavior surveillance - United States, 2017. MMWR SurveillSumm 67: 1-114.

46. Simonetti JA, Mackelprang JL, Rowhani-Rahbar A, Zatzick D, Rivara FP et al. (2015) Psychiatric Comorbidity, suicidality, and in-home firearm access among a nationally representative sample of adolescents. JAMA Psychiatry

47. Kleck G (2015) The impact of gun ownership rates on crime rates: A methodological review of the evidence. J Criminal Justice 43: 40-48.

48. Arp J, Gonzales R, Herstand M, Wilson M (2017) Gun violence in the American culture. Social Justice Brief. National Association of Social Workers.

49. Glover I (2014) Role-play: An Approach to Teaching and Learning. 